\title{
A new Caribbean species of Hylaeanura Arlé, 1966 (Collembola, Neanuridae, Pseudachorutinae)
}

\author{
Claudia M. Ospina-Sánchez', José G. Palacios-Vargas², Grizelle González' \\ I USDA-FS, International Institute of Tropical Forestry, Río Piedras, 00926-1119, Puerto Rico 2 Laboratorio \\ de Ecología y Sistemática de Microartrópodos, Departamento de Ecología y Recursos Naturales, Facultad de \\ Ciencias, Universidad Nacional Autónoma de México, 04510 México, D.F., México
}

Corresponding author: Claudia M. Ospina-Sánchez (cmarcela.ospinas@gmail.com)

Academic editor: Wanda M. Weiner | Received 10 October 2019 | Accepted 23 July 2020 | Published 19 August 2020

http://zoobank.org/0155C74B-3816-42F3-B221-OB5CB57A291D

Citation: Ospina-Sánchez CM, Palacios-Vargas JG, González G (2020) A new Caribbean species of Hylaeanura Arlé, 1966 (Collembola, Neanuridae, Pseudachorutinae). ZooKeys 961: 31-39. https://doi.org/10.3897/zookeys.961.47227

\begin{abstract}
We here describe a new Collembola species, Hylaeanura emiliae sp. nov., from the Luquillo Experimental Forest in Puerto Rico. We describe H. emiliae sp. nov. as a distinct species based on the enlarged sensilla s3 in antennal segment IV, the absence of modified sensorial setae in abdominal segment IV and the presence of four setae on each dens. An updated key with illustrations for the identification of worldwide species of the genus is included.
\end{abstract}

\section{Keywords}

Island, Luquillo Experimental Forest, Puerto Rico, subtropical forest, taxonomy

\section{Introduction}

In Puerto Rico, most studies of arthropod community dynamics have been performed in the Luquillo Mountains (Richardson 1999; González and Barberena 2017; Quiñones et al. 2018). The Luquillo Experimental Forest (LEF) contains four forest types defined by elevation and distinct tree species composition (Gould et al. 2006; Weaver and Gould 2013). The present study focuses on three of them: (1) The Tabonuco (Dacryodes excelsa Vahl) forest occupies areas below $600 \mathrm{~m}$, (2) the mid-elevation, Palo Colorado (Cyrilla racemiflora L.) forest occurs in areas above the cloud conden- 
sation level from 600-900 m, and (3) the Elfin forest (Tabebuia rigida Urban), with stunted vegetation and waterlogged anoxic soils, is located only on the highest peaks above $900 \mathrm{~m}$ (Gould et al. 2006). These forests represent the subtropical wet and subtropical rain forest life zones in Puerto Rico (Ewel and Whitmore 1973).

In most studies of litter and soil fauna in the LEF, Collembola are an important group for ecosystem functioning because of their dominant abundance and their key responses to changes in disturbance, altitude and vegetation type (Schowalter and Ganio 1999; Schowalter et al. 2003; Richardson et al. 2005; Richardson et al. 2010; Schowalter et al. 2014). In Puerto Rico, collembolans are well known in comparison to other groups of soil arthropods. However, not all Collembola species from LEF have been identified (González and Barberena 2017). In a recent survey made between 2014 and 2015, 16 families 37 genera and 60 species/morphospecies were identified, and among these, 15 are new species to science (Ospina-Sánchez 2019). The purpose of this paper is to describe a new species of Hylaeanura Arlé, 1966.

The genus Hylaeanura was conceived by Arlé (1966) to place Paranurella infima described by himself in 1959. So far only four species are known: Hylaeanura nepalensis (Yosii, 1966), originally described as Paranura nepalensis from the Himalayas; H. nobbecana Vázquez, Cutz-Pool \& Palacios-Vargas, 1998, from Mexico; H. mendoncae Zeppelini \& Palacios-Vargas, 2013, from Brazil and H. infima from Brazil, French Guiana and Peru (Najt et al. 1990). The first taxonomic report of the genus from Puerto Rico was H. infima (Ospina-Sánchez et al. 2020) and it now includes the new species Hylaeanura emiliae.

\section{Materials and methods}

The material used to describe the new Hylaeanura species came from the survey of the Collembola microhabitats in the Luquillo Mountains conducted in 2014 and 2015 along three forest types (Tabonuco, Dacryodes excelsa; Palo Colorado, Cyrilla racemiflora and Elfin forest, Tabebuia rigida). Collembola were extracted from soil and litter samples using a Berlese-Tullgren funnel and stored in 95\% ethanol. They were cleared using Nesbitt solution and fixed in slides using Mac André II solution (Mari Mutt 1976). To harden the solution, the slides were dried in a slide warmer at 45 to $50{ }^{\circ} \mathrm{C}$ for seven days. Finally, each specimen was labeled with its collecting data. Specimens were examined with a Leica DM500 phase-contrast microscope. The drawings were made with the aid of a drawing tube.

\section{Abbreviations:}

a.s.l. above sea level

Abd abdominal segment

Ant antennal segment

PAO Postantennal Organ

$S$ sensilla
Sgd dorsal guard sensillum of Ant III

Sgv ventral guard sensillum of Ant III

ss sensorial setae

Tita tibiotarsi

Th thoracic segment 


\section{Taxonomy}

\section{Poduromorpha}

Neanuridae

Pseudachorutinae

\section{Hylaeanura Arlé, 1966}

Diagnosis (modified from Zeppelini and Palacios-Vargas 2013). Habitus of Paranurella or Kenyura, i.e., reduced appendices and without pigment; less than $1.0 \mathrm{~mm}$ in size; without eyes or at most 2 eyes per side; antennae shorter than half the cephalic diagonal, Ant. IV with 7 sensilla, S8 hypertrophied; mandible with one to three teeth, maxilla styliform; legs very short, ungues without teeth and unguiculus, tenent hairs not developed. Ventral tube with $3+3$ setae; tenaculum $2+2$ to $3+3$, furcula very reduced, each dens with 3 setae, mucro minute or lacking. Body chaetotaxy reduced and with very small setae.

\section{Hylaeanura emiliae sp. nov.}

http://zoobank.org/7361B653-81A6-4781-9F58-9CF8AAA05CCE

Figures $1-9$, Table 1

Type material. Holotype. Female on slide. Paratypes: 1 female and 1 juvenile on slide. All the type material kept at corresponding author's institution.

Type locality. Puerto Rico, Luquillo, Luquillo Mountains, Toro Trail $1,18^{\circ} 16^{\prime} 40^{\prime \prime} \mathrm{N}, 65^{\circ} 50^{\prime} 53^{\prime \prime W} ; 815 \mathrm{~m}$ a.s.l.; ex soil, Cyrilla racemiflora forest type, 18 November 2014. All specimens were extracted using Berlese-Tullgren funnels from samples collected in leaf litter and soil at the Luquillo Mountains. C. M. Ospina and M. Rivera leg.

Other material. Female on slide, Puerto Rico, Luquillo, Luquillo Mountains, Toro Trail 2, $18^{\circ} 16^{\prime} 40.3^{\prime \prime} \mathrm{N}, 65^{\circ} 51^{\prime} 01^{\prime \prime W}$, Cyrilla racemiflora forest type, leaf litter, 795 m a.s.l., 18 November 2014, C.M.Ospina leg. One (1) juvenile on slide, Puerto Rico, Luquillo, Luquillo Mountains, Toro Trail 1, 18 $16^{\prime} 40^{\prime \prime N}$, $65^{\circ} 50^{\prime} 53^{\prime \prime W}$, Cyrilla racemiflora forest type, leaf litter, $815 \mathrm{~m}$ a.s.l., 18 February 2015, C. M. Ospina leg.

Diagnosis. Hylaeanura emiliae sp. nov. has an enlarged sensillas S3 and S8 on Ant IV, Abd IV without modified setae, and four setae on each dens.

Description. Length of the holotype $1050 \mu \mathrm{m}$ (female paratype $653 \mu \mathrm{m}$ and juvenile paratype $550 \mu \mathrm{m}$ ). Specimens in ethanol without color, body with coarse granulation and without tubercles. Body setae short and smooth, the sensorial setae longer than ordinary setae, both acuminate (Fig. 1).

Head: Antenna smaller $(0.47 x)$ than cephalic diagonal. Ant III and IV fused dorsally. Ant IV dorsally with a trilobed apical vesicle; subapical organite absent and dorsoexternal microsensillum, 7 subcylindrical sensilla, S8 hypertrophied, S7 

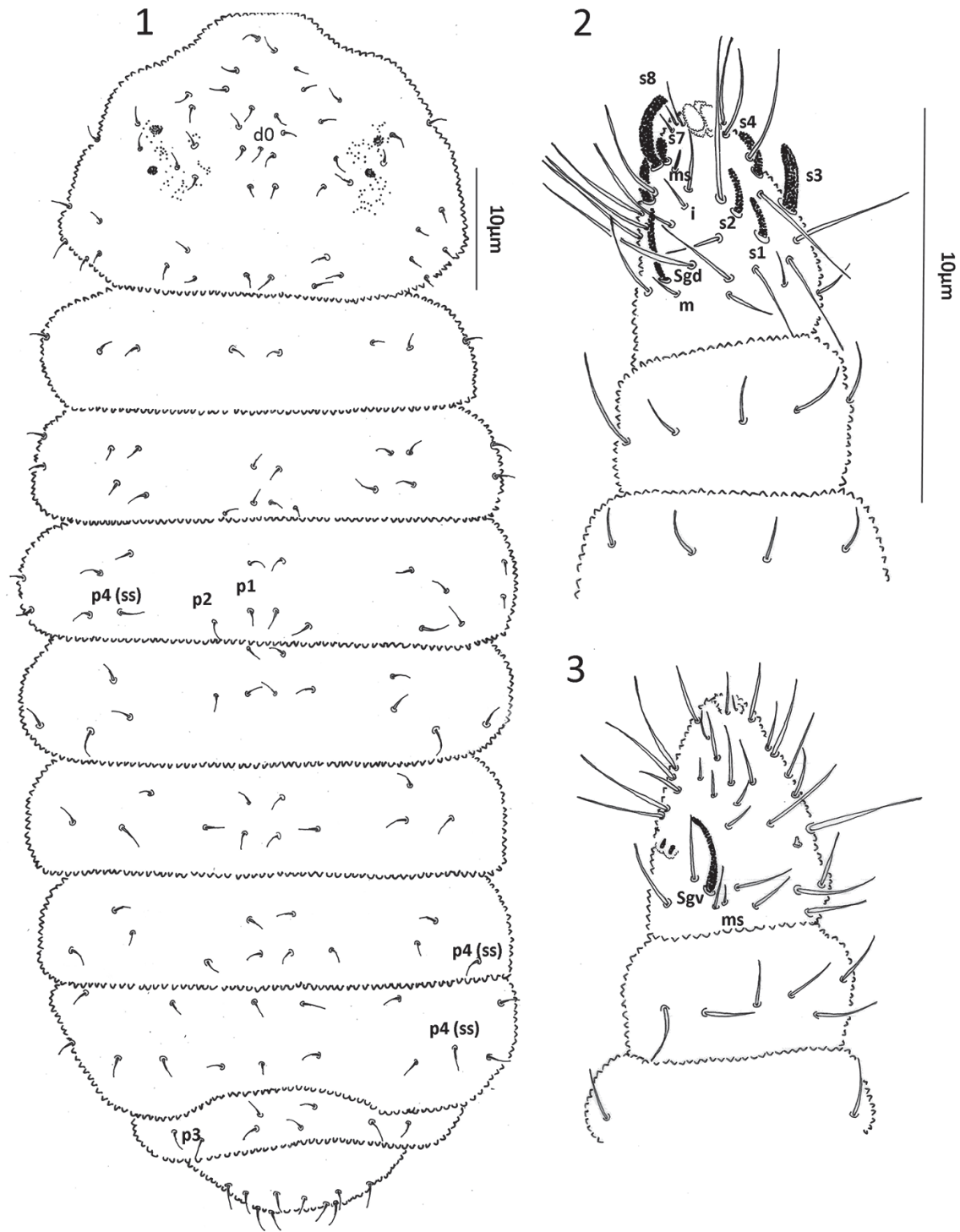

\section{3}

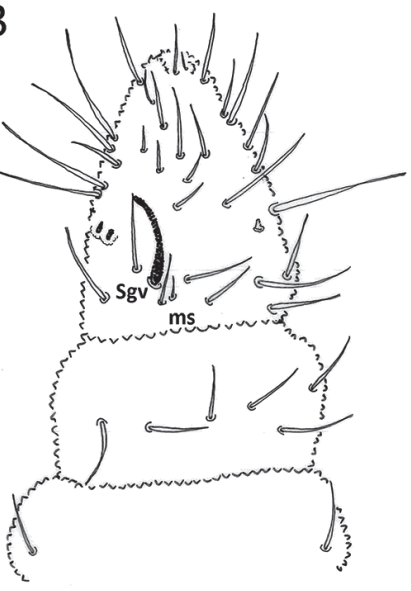

Figures I-3. Hylaeanura emiliae sp. nov. I Dorsal chaetotaxy 2 Ant. I-IV dorsal view 3 Ant. I-IV ventral view.

smaller and S3 large; 12 long setae plus i (Fig. 2); Ant III sense organ with two small internal straight sensilla and two subequal subcylindrical guard sensilla; ventral microsensillum present (Fig. 3); Ant II with 11 setae; Ant I with six setae. Eyes $2+2$ in a pigmented patch. PAO absent. Head dorsal quetotaxy as in Fig. 1, unpaired setae $\mathrm{d} 0$ present. Labium with a total of 11 setae per side with setae A to G, setae C and D slightly displaced apically (Fig. 4). Labral chaetotaxy 4, 2, 2 (Fig. 5). Mandible with one tooth, maxilla styliform (Fig. 6). 

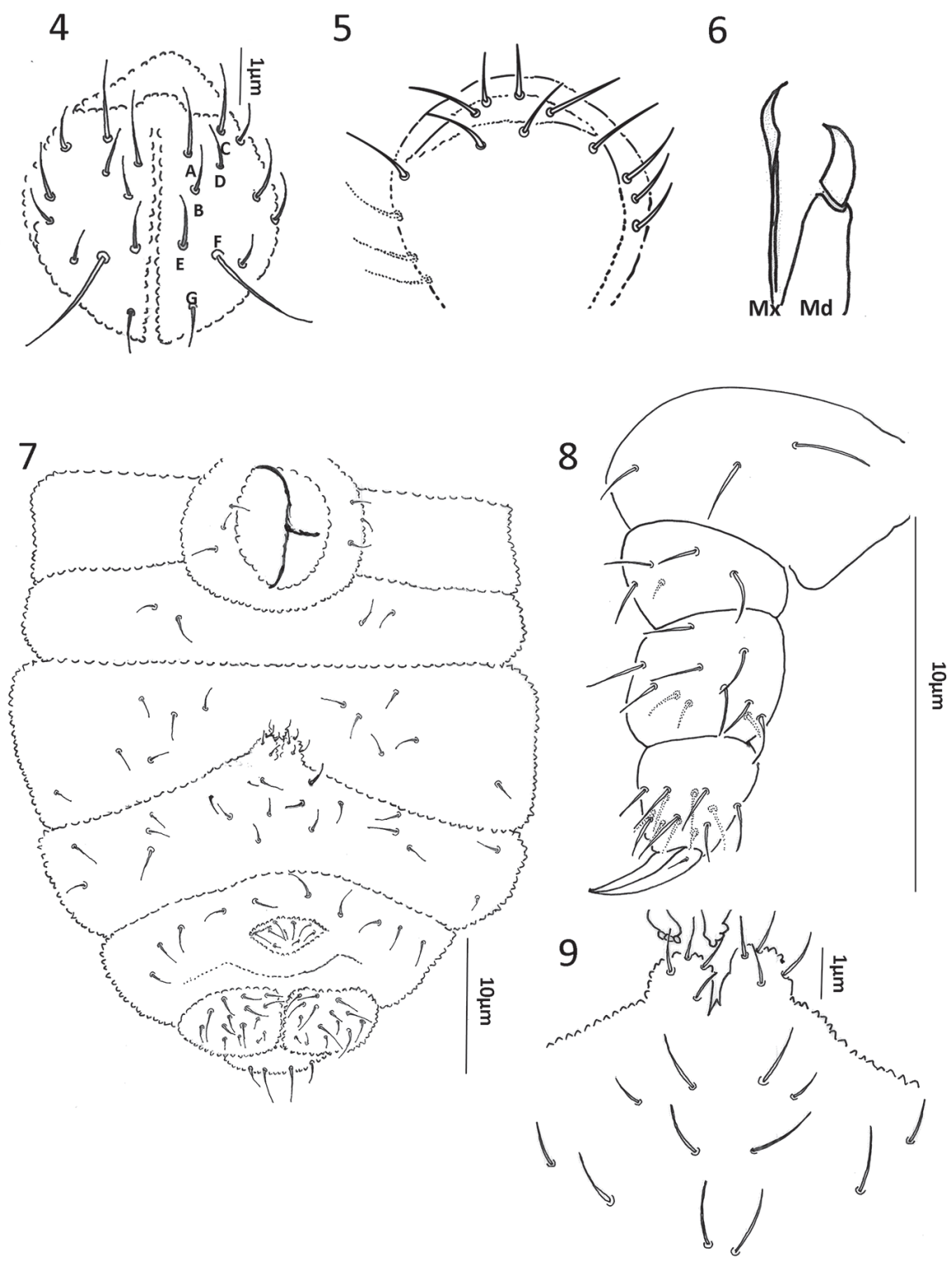

Figures 4-9. Hylaeanura emiliae sp. nov. 4 Labium 5 Labrum 6 Mandible (Md) and Maxillae (Mx) $\mathbf{7}$ Ventral abdominal chaetotaxy 8 leg I 9 reduced furcula and tenaculum.

Body: Ordinary body setae smooth, distributed as in Fig. 1. Th I with $3+3$ setae. Sensory setae (ss) similar to body setae, in position $\mathrm{p} 4$ in all segments and distributed on Th. II-Abd V as 11/11111. Ventral chaetotaxy as in Fig. 7. Female genital plate with $3+3$ pregenital setae, 7 circumgenital and 2 eugenital (Fig. 7). Male genital plate not seen. Each anal ventral lobe with 14 setae. 
Table I. Summary of main characters of described species of Hylaeanura Arlé, 1966.

\begin{tabular}{|c|c|c|c|c|c|c|c|c|c|c|}
\hline Species & $\begin{array}{c}\text { Total } \\
\text { length } \\
(\mu)\end{array}$ & $\begin{array}{c}\text { Ventral } \\
\text { guard } \\
\text { sensillum }\end{array}$ & $\begin{array}{c}\text { Dorsal } \\
\text { guard } \\
\text { sensillum }\end{array}$ & $\begin{array}{l}\text { Mandible } \\
\text { teeth }\end{array}$ & $\begin{array}{c}\text { Eyes per } \\
\text { side of } \\
\text { head }\end{array}$ & $\begin{array}{l}\text { Shape Abd } \\
\text { IV sensillum }\end{array}$ & $\begin{array}{c}\text { Tenaculum } \\
\text { teeth }\end{array}$ & $\begin{array}{l}\text { Setae in } \\
\text { dens }\end{array}$ & $\begin{array}{c}\text { Setae in } \\
\text { manubrium }\end{array}$ & Mucro \\
\hline H. infima & 500 & st & st & 2 & 0 & ss & $?$ & 3 & 2 & - \\
\hline H. nobbecana & 1000 & st & st & 3 & 0 & $\mathrm{cf}$ & $3+3$ & 3 & 2 & + \\
\hline H. nepalensis & 700 & st & st & 3 & 2 & ss & $2+2$ & 3 & 2 & - \\
\hline H. mendoncae & 600 & si & si & 2 & 2 & ss & $2+2$ & 3 & $0(6)$ & - \\
\hline H. emiliae sp. nov. & 850 & st & st & 1 & 2 & ss & $3+3$ & 4 & $0(6)$ & - \\
\hline
\end{tabular}

st, straight

si, sinuous

cf, candle-flame shaped

ss, sensillum acuminated

?, no information included in the original description

-, absent

+ , present

Legs: Chaetotaxy of legs I-III as follow: Coxae with 3, 5, 7 trochanter with 5, 5, 4; femora 11,11, 10 and tita with 16, 16, 14 setae (Fig. 8). Tenent hair not developed and unguiculus absent; claws without teeth.

Collophore with $3+3$ setae; tenaculum with $3+3$ teeth and without setae; furcula reduced, manubrium reduce with $6+6$ setae in Abd III ventrally; dens with four setae, mucro absent (Fig. 9).

Etymology. This species is dedicated to the daughter of the senior author, Emilia, who was born while this research was being conducted.

Distribution. Hylaeanura emiliae sp. nov. is only known from the Luquillo Mountains in the Cyrilla racemiflora forest type, on the Toro Trail between $795-815 \mathrm{~m}$ a.s.l.

Fenology. Hylaeanura emiliae sp. nov. was extracted from leaf litter and soil in both dry and rainy seasons during November 2014 and May and August 2015.

Identification key to the species of Hylaeanura Arlé, 1966

(updated from Zeppelini and Palacios-Vargas 2013)

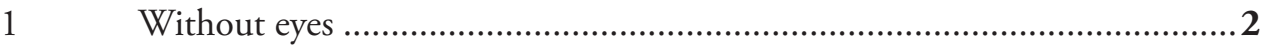

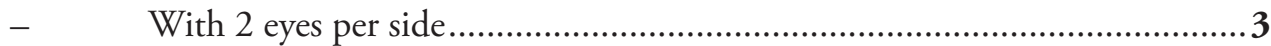

2 Sensorial seta on Abd IV candle-flame shaped. Dens with a minute mucro present .......... H. nobbecana Vázquez, Cutz-Pool \& Palacios-Vargas, 1998 Sensorial seta on Abd IV sensillum shaped. Dens without mucro ..

H. infima (Arlé, 1959)

3 Dorsal and ventral guard sensilla sinuous (Sensorial organ Ant Ill). Mandible with two teeth.............. H. mendoncae Zeppelini \& Palacios-Vargas, 2013

- $\quad$ Dorsal and ventral guard sensilla straight, Mandible with 1 or 3 teeth ........4

4 Tenaculum with $2+2$ teeth. Mandible with 3 teeth

H. nepalensis (Yosii, 1966)

- $\quad$ Tenaculum with $3+3$ teeth. Mandible with 1 tooth..........H. emiliae sp. nov. 


\section{Discussion}

The description of Hylaeanura emiliae sp. nov. fits with the most recent genus diagnosis proposed by Zeppelini and Palacios-Vargas (2013). Although in the diagnosis of the genus, the dens each have three setae and $H$. emiliae sp. nov. has four setae in each, the number of setae on the dens, as well as the shape of the mucro, are variable characters among the species (D’Haese 2003). The similar genus Kenyura includes species having numerous teeth on the mandible, S8 is normal and the presence of pigmentation (Arlé 1966, Vázquez et al. 1998).

Hylaeanura emiliae sp. nov. is different from other Hylaeanura due to the enlargement of the sensilla 33 in Ant IV, the absence of modified S setae in Abd IV and the presence of four setae in the dens. Additionally, it has an unpaired seta $\mathrm{d} 0$ in the head. This setae is absent in other described species of the genus, but defines a unique difference within head chaetotaxy.

Using the comparative morphology of Hylaeanura presented by Zeppelini and Palacios-Vargas (2013), the character combination of the new species is different from all others previously described. According to their descriptions the most similar is $\mathrm{Hy}$ laeanura nepalensis, but it differs in size, the presence of $2+2$ tenacular teeth and three mandibular teeth (Yosii 1966).

Hylaeanura infima is the smallest species and has a sensillum of Abd IV of setae shape. It differs from the new species by the absence of eyes and the presence of two teeth in the mandible and the presence of three setae in dens (Arlé 1966, Thibaud and Massoud 1983).

Hylaeanura nobbecana is the biggest Hylaeanura, and is similar to the new species in the straight shape of the guard sensillum of Ant IV, the differences appearing in the chaetotaxy: the absence of unpaired setae $\mathrm{d} 0$ in the head, the presence of setae a 3 in Abd II-IV and the position of the ss in $\mathrm{p} 3$ in Abd I. Additionally, $H$. nobbecana has no eyes, the furcula has two small dens each bearing 3 setae and a small vestigial mucro (Vázquez et al. 1998).

The most recently described species, $H$. mendoncae differs from $H$. emiliae sp. nov. in the position of ss in Abd I to III in p3. In Abd IV, ss is also in position $\mathrm{p} 3$ but in the shape of a candle-flame setae. In Abd V ss is in position p2. The furcula is reduced and dens have 3 setae each without a mucro (Zeppelini and Palacios-Vargas 2013). Similar to H. emiliae sp. nov., $H$. mendoncae has $6+6$ setae present ventrally in Abd III as vestigial manubrium. The differences between described Hylaeanura species are described in Table 1.

\section{Acknowledgements}

This research was supported by Grant DEB 1239764 and 1546686 from the US National Science Foundation to the Institute for Tropical Ecosystem Studies, University of Puerto Rico, and to the International Institute of Tropical Forestry (IITF) USDA Forest Service, as part of the Luquillo Long-Term Ecological Research Program. The US Forest Service (Department of Agriculture) Research and Development Unit, and the University of Puerto Rico provided additional support. We thank to María M. Rivera (IITF) for field work help. 


\section{References}

Arlé R (1966) Collemboles d'Amazonie, I. Poduromorphes nouveaux ou peu connus et notes biologiques sur Neotropiella carli (Denis). Boletim do Museu Paraense Emilio Goeldi, nova serie, zoologia 60: 1-19.

D'Haese CA (2003) Homology and morphology in Poduromorpha (Hexapoda, Collembola). European Journal of Entomology 100: 385-407. https://doi.org/10.14411/eje.2003.060

Ewel JJ, Whitmore JL (1973) Ecological life zones of Puerto Rico and US Virgin Islands. Ecological life zones of Puerto Rico and US Virgin Islands. USDA Forest Service, Institute of Tropical Forestry, Research Paper ITF-018.

González G, Barberena MF (2017) Ecology of soil arthropod fauna in tropical forests: A review of studies from Puerto Rico. The Journal of Agriculture of the University of Puerto Rico 101: 185-201.

Gould W, González G, Carrero Rivera G (2006) Structure and composition of vegetation along an elevational gradient in Puerto Rico. Journal of Vegetation Science 17: 653-664. https:// doi.org/10.1111/j.1654-1103.2006.tb02489.x

Mari Mutt JA (1976) Genera of Collembola (Insecta) in Puerto Rico: keys, diagnoses, and general comments. Journal of Agriculture of the University of Puerto Rico 60: 113-128.

Najt J, Thibaud JM, Weiner WM (1990) Collemboles (Insecta) Poduromorphes de Guyane française. Bulletin du Muséum National d'Histoire Naturelle 4: 95-121.

Ospina-Sánchez CM (2019) Role of Microhabitats and Environment Variation on Collembola (Hexapoda: Entognatha) Populations in The Luquillo Experimental Forest: A Montane Environment. PhD Thesis, University of Puerto Rico, Rio Piedras campus.

Ospina-Sánchez CM, Soto-Adames FN, González G (2020) Checklist and distribution of Collembola from Greater Puerto Rico. Biodiversity Data Journal 8: e52054. https://doi. org/10.3897/BDJ.8.e52054

Quiñones M, Parés-Ramos IK, Gould WA, González G, McGinley K, Ríos P (2018) El Yunque National Forest Atlas. International Institute of Tropical Forestry, San Juan, 63 pp.

Richardson BA (1999) The Bromeliad Microcosm and the Assessment of Faunal Diversity in a Neotropical Forest. Biotropica 31: 321-336. https://doi.org/10.1111/j.1744-7429.1999. tb00144.x

Richardson BA, Richardson MJ, Soto-Adames FN (2005) Separating the effects of forest type and elevation on the diversity of litter invertebrate communities in a humid tropical forest in Puerto Rico. Journal of Animal Ecology 74: 926-936. https://doi.org/10.1111/j.13652656.2005.00990.x

Richardson BA, Richardson MJ, González G, Shiels AB, Srivastava DS (2010) A canopy trimming experiment in Puerto Rico: the response of litter invertebrate communities to canopy loss and debris deposition in a tropical forest subject to hurricanes. Ecosystems 13: 286301. https://doi.org/10.1007/s10021-010-9317-6

Schowalter TD, Ganio L (1999) Invertebrate communities in a tropical rain forest canopy in Puerto Rico following Hurricane Hugo. Ecological Entomology 24: 191-201. https://doi. org/10.1046/j.1365-2311.1999.00186.x 
Schowalter TD, Ganio LM, Basset Y, Novotny V, Miller S, Kitching R (2003) Diel, seasonal and disturbance-induced variation in invertebrate assemblages. In Basset Y, Kitching R, Miller S, Novotny V (Eds) Arthropods of Tropical Forests: Spatio-Temporal Dynamics and Resource Use in the Canopy. Cambridge University Press, Cambridge, 315-328.

Schowalter TD, Willig MR, Presley SJ (2014) Canopy arthropod responses to experimental canopy opening and debris deposition in a tropical rainforest subject to hurricanes. Forest Ecology and Management 332: 93-102. https://doi.org/10.1016/j.foreco.2013.12.008

Thibaud JM, Massoud Z (1983) Collemboles des Petites Antilles. III. Neanuridae (Pseudachorutinae). Revue d'Écologie et de Biologie du Sol 20: 111-129

Vázquez M, Cutz Pool L, Palacios-Vargas JG (1998) A new species of Hylaeanura (Collembola: Neanuridae: Pseudachorutinae). The Southwestern Entomologist 23: 367-371

Weaver PL, Gould WA (2013) Forest vegetation along environmental gradients in northeastern Puerto Rico. In: G González, MR Willig, RB Waide (Eds) Ecological Gradient Analyses in a Tropical Landscape. Ecological Bulletins 54, Wiley-Blackwell, Hoboken, 43-66.

Yosii R (1966) Collembola of Himalaya. Journal of the College of Arts and Sciences. Chiba University 4: 461-531.

Zeppelini D, Palacios-Vargas JG (2013) A new Brazilian species of Hylaeanura (Collembola: Neanuridae). Florida Entomologist 96: 1401-1405. https://doi.org/10.1653/024.096.0419 